\title{
Relating Cultural Values with Opportunity Evaluation

\author{
Evidence from India
}

\author{
A. Banu Goktan \\ Alka Gupta \\ Subhendu Mukherjee \\ Vishal K. Gupta
}

\begin{abstract}
$T_{0}^{\text {then }}$ he link between social interaction and entrepreneurial activity has attracted considerable attention in the entrepreneurship literature. In this study, we focus on individual cultural values, shaped by interactions in the social space, as they relate to opportunity evaluation, a cornerstone of the entrepreneurial process. We test our predictions in India, a non-Western society that has sustained one of the highest rates of entrepreneurial activity in the world. Our findings suggest that value orientation of high power distance is negatively associated with opportunity evaluation whereas uncertainty avoidance, collectivism, and femininity are positively associated with opportunity evaluation.
\end{abstract}

Keywords: cultural values, opportunity evaluation, India

After the so-called Great Recession that followed the global financial crisis at the end of 2007 (Bell \& Blanchflower, 2011), interest in entrepreneurship from policy makers and business leaders around the world increased. Entrepreneurship is viewed as a means to revitalize the economy and stimulate growth (Thomas \& Mueller, 2000). Researchers have seen renewed interest in understanding entrepreneurial activity across societies worldwide. They have also recognized that findings of the studies conducted in the United States and Western Europe may not always be transferable to the rest of the world (Thomas \& Mueller, 2000).

Culture is an important contextual factor that affects potential entrepreneurial activity in a society at the macro level (Hayton, George, \& Zahra, 2002). At the individual level, on the other hand, cultural values influence the degree to which entrepreneurial behaviors are considered desirable by entrepreneurs. They represent the values and beliefs that provide the immediate context in which entrepreneurial behavior emerges. The association between culture and entrepreneurship has been drawing attention since the 1990s. Only a few entrepreneurship studies have focused on the individual level, although individual level studies are common in culture research (Kirkman, Lowe, \& Gibson, 2006). In addition, none of these studies have investigated the influence of cultural values on opportunity evaluation, even though evaluation of new business opportunities is considered a cornerstone of entrepreneurship research (Shane \& Venkataraman, 2000). Consequently, examination of the relationship between individually held cultural values and the factors and processes associated with assessments of entrepreneurial opportunities is largely ignored in the literature (Haynie et al., 2009). Identifying and understanding factors that influence why, when, and how some people, but not others, favorably assess new opportunities to introduce novel goods and services has emerged as an important research agenda in the last decade (Eckardt \& Shane, 2003). Understanding the relationship between cultural values and entrepreneurship can provide valuable information for governments to develop programs through which new ventures are created and employment increased (Thomas \& Mueller, 2000).

We theoretically elaborate and empirically examine the relationship between cultural values and opportunity evaluation in this study. Our research seeks to contribute to the small but engaging literature on antecedents of opportunity evaluation (Foo, 2011). We also extend research on values and beliefs to entrepreneurship in general, and opportunity evaluation in particular. We empirically test our predictions in India, extending opportunity evaluation research to non-Western societies. Most research in the field of entrepreneurship has been generated in the U.S. and Western Europe. However, "transferability of U.S. research to non-U.S. contexts is not universal" (Thomas \& Mueller, 2000, p. 289). India has one of the highest rates of entrepreneurial activity in the world (Khanna, 2008), which makes it a suitable country to examine our predictions.

6 NEW ENGLAND JOURNAL OF ENTREPRENEURSHIP 


\section{Theory and Hypotheses}

Entrepreneurship research is multidisciplinary in nature, which is particularly appropriate as the field of entrepreneurship is "complex, dynamic and interactive... [with] the entrepreneur at the center" (Etemad, 2004, p. 8). Schumpeter (1934) was the first to suggest that the entrepreneur is a generator of economic growth. Entrepreneurship cannot exist without individuals who see opportunities where others cannot (Shinnar et al., 2012) and without individuals who show intent and act upon those opportunities (Liñán \& Chen, 2009).

At the macro level, some of the factors that affect entrepreneurship include industry, competition, social institutions, networks, and financial resources, among others (Brandstätter, 2011). At the individual level, the focus has been on personality including risk propensity (Rauch \& Frese, 2007; Stewart \& Roth, 2001; Zhao \& Seibert, 2006; Zhao, Seibert, \& Lumpkin, 2010), achievement motivation (Collins, Hanges, \& Locke, 2004; Stewart \& Roth, 2007) and the Big Five personality theory (Zhao \& Seibert, 2006). However, cognitive processes and values, although equally important, have been neglected (Brandstätter, 2011). In this study, we address both issues by focusing on cultural values and the cognitive process of opportunity evaluation.

\section{Opportunity Evaluation}

The entrepreneurial process involves the complex and intertwined functions, activities, and actions associated with recognizing and pursuing new business opportunities (Keh et al., 2002). Opportunity evaluation is a behavioral task involving analysis and intuition to identify meaningful patterns in ambiguous information about emergent events and trends (Baron \& Ensley, 2006). Entrepreneurs often see opportunities where others do not, and envision future possibilities that others fail to recognize. Deciding whether a situation is a business opportunity involves judgments made under conditions of uncertainty and complexity (Shane \& Eckhardt, 2005). Whether it is to start a company or introduce novel goods and services to the market, opportunity evaluation is at the heart of the entrepreneurial process (Shepherd \& DeTienne, 2005). An enterprising individual can be immensely creative and hardworking, but unless a business opportunity is perceived to be desirable or feasible, it will not be acted upon, and new products, technologies, and services will not be introduced (Eckhardt \& Shane, 2003). A particular opportunity is evaluated favorably when "individuals recognize opportunities for themselves and make the decision to act on these opportunities in the face of uncertainty" (Mitchell \& Shepherd 2010, p. 140).
One of the factors that shape the assessment of new opportunities is the values and beliefs of the enterprising individual (Goktan \& Gunay, 2011). Indeed, values and beliefs have been shown to impact several work-related attitudes and behaviors, such as motivation to lead (Chan \& Drasgow, 2001), attitudes toward cooperative strategies (Steensma et al., 2000), and organizational citizenship behaviors (Moorman \& Blakely 1995), among others (Kirkman et al., 2006). Therefore, individual cultural values, which often represent the way people see the world and behave, are likely to affect whether an opportunity is perceived as favorable or not.

\section{Individual Cultural Values}

Research from a variety of perspectives suggests that outcomes on cognitive tasks like evaluation of new opportunities are influenced by core values that people hold. Values are beliefs that pertain to desirable end states and they guide individuals in choosing behaviors and determining priorities (Schwartz \& Bilsky, 1987, 1990). Values emerge in response to basic issues of survival and growth (Kirkman et al., 2006), help individuals understand and manage the "complex reality of our social world" (Hofstede, 2006, p. 895) and are shaped by interactions with others (van Maanen, 1989; Ashforth \& Mael, 1989). Social interactionism holds that values are learned and acquired from the verbal and nonverbal interactions of individuals (Fine, 1993) whereas symbolic interactionism theory (Fine, 1993) suggests that individuals acquire values and beliefs through social and cultural interactions.

Several researchers have tried to classify values (e.g., Rokeach, 1973; Levitin, 1973; Schwartz, 1992) with varying degrees of success. There are a variety of frameworks to capture core values and beliefs, but perhaps the most influential, especially in regards to the interactional nature of values, is the one offered by Geert Hofstede. The majority of culture studies have used Hofstede's (1980) conceptualization of cultural values and frequently adopted his four-dimensional framework (Hayton, George, Zahra, 2002). Hofstede (1980) deconstructed the individual value system into four basic core dimensions: power distance, uncertainty avoidance, individualism, and masculinity. These four facets, Hofstede (1991, p. 35) argued, represent "core elements" of the value system, and can be used to meaningfully describe values and beliefs worldwide (Hofstede, 2002).

A fifth dimension of long-term versus short-term orientation was developed by Michael Harris Bond in 1991, and a sixth dimension of indulgence versus restraint 
was developed by Michael Minkov in 2010 (Hofstede, 2001; Hofstede at al., 2010). However, these dimensions are neither part of the original Hofstede model nor have they been embraced as widely as the four original dimensions (Taras, Steel, \& Kirkman, 2012). The "time orientation" dimension, which was designed by Chinese scholars, for example, has proven to have limited validity outside China, and therefore its application has been limited (Hofstede, Hofstede, \& Minkov, 2010). Despite some criticism (e.g., Baskerville, 2003; McSweeney, 2002), the four-dimensional conceptualization has become the dominant paradigm in cross-cultural studies (Kirkman et al., 2006; Taras et al., 2010).

Contemporary researchers generally consider the four-dimensional framework as "a reasonable way" to make sense of values and beliefs (Ralston et al., 2007, p. 2). More than three decades have passed since the introduction of the framework, and in this time it has gained tremendous popularity in psychological and organizational research (Hofstede, 2006). The four-dimensional cultural framework is not without its critics (e.g., Baskerville, 2003; McSweeney, 2002) who charge that the methodology Hofstede used to come up with the four dimensions is flawed as it relies on small sample sizes, assumes homogeneity within the country, and reflects the views of respondents employed within one large, multinational corporation. Yet, the four-dimensional conceptualization has continued to be the dominant paradigm in research on cultural values in the social sciences (Kirkman et al., 2006). This is likely because hundreds of independent studies-including a large number in recent years - have heavily replicated Hofstede's typology and found support for its fourdimensional framework (Taras et al., 2012). According to Hofstede (2006), "the dimensions paradigm... has become the 'normal science' approach" to cultural values research in business and organizational studies (p. 883). The scale of acceptance of the Hofstede framework (average 90+ SSCl citations per annum since 1980 and more than 25,000 total citations in 30 years) has led many to claim that it is a modern classic (Venaik \& Brewer, 2010) that has heralded "a true paradigm shift" in cultural values research (Hofstede, 1998, p. 480), especially in organizational and psychological studies (Smith, 2002).

When conceived as individual-held cultural values, endorsement of the four descriptors-power distance, uncertainty avoidance, individualism, and masculinityreflect a "pattern of construct variation unique to the individual" (Triandis et al., 1990). Power distance is the extent to which unequal distribution of power is considered acceptable and legitimate (Smith \& Hume, 2005). The notion of power distance is manifested in obedience to people in authority versus striving for egalitarianism. Uncertainty avoidance refers to lack of tolerance for ambiguity and absence of structure (Dorfman \& Howell, 1988). It indicates discomfort with and unacceptability of operating in unstructured and uncertain situations. Individualism is the degree to which individual interests are considered subordinate to the interest of the group (e.g., family) (Kagitcibasi, 1997). It involves elevating personal aspirations ahead of group goals, as opposed to making the self clearly subservient to the group (Robert et al., 2000). Masculinity indicates preference for "tough" concerns such as competition and achievement (Emrich et al., 2004). It corresponds to the male stereotype of having a higher proclivity for autonomy, exhibition, and dominance, as opposed to a preference for "soft" characteristics such as agreeableness and affiliation (Hofstede, 1998). These values shape the way individuals organize knowledge and social behavior into a fairly consistent set of psychological orientations that reflect "a broad tendency to prefer a certain set of affairs over others" (Mitchell et al., 2000, p. 979). Robert and Wasti (2002, p. 545) note that cultural values "help one organize and interpret the world by focusing attention on certain patterns or themes in the subjective elements of the environment." Prior research has considered these individual-level cultural values in withincountry research (Colquitt, 2004; Colquitt et al., 2002) as well as in cross-country studies (Gomez et al., 2000; Kirkman \& Shapiro, 2001).

Thus, the present study focuses on the four core dimensions that have been the most relevant to management researchers, including those studying entrepreneurial phenomenon (Hayton, George, Zahra, 2002). Hofstede's cultural framework involves multidimensional conceptualization of bi-polar cultural factors (Sharma, 2010). Each cultural dimension ranges from, for example, extreme masculinity at one end to extreme femininity at the other (Constantinople, 2005). Past research suggests that the four core values may be particularly pertinent in understanding business-related attitudes and behaviors (Kirkman et al., 2006). Indeed, researchers have specifically confirmed the relevance of Hofstede's cultural dimensions to business issues (including studies in fields as diverse as management, finance, and MIS) and also found them to be practically useful for managers and practitioners working in international settings (Taras et al., 2012). We now link the

8 NEW ENGLAND JOURNAL OF ENTREPRENEURSHIP 
four values of power distance, uncertainty avoidance, individualism, and masculinity with opportunity evaluation, a cognitive task that requires individuals to "connect the dots" between seemingly disparate bits of information (Baron \& Ensley, 2006).

Power distance. Power distance refers to the acceptance of inequality in power and authority between individuals. Everyone is believed to have a place in society — some are high, some are low_-and powerful people are entitled to privileges not available to others. The idea that power is distributed unequally is expected and accepted (Hofstede \& Hofstede, 2005). In this worldview, those in power are seen as having a higher place in society, and individuals who are in the lower echelons of the society are expected to obey those in power (Hofstede, 1980). Research suggests that dependence on people of higher authority is likely to limit the autonomy of the individuals (Goktan \& Gunay, 2011). Previous studies suggest that entrepreneurship is cultivated when individuals perceive that they have autonomy and control over their work and ideas (Amabile et al., 1996), whereas entrepreneurial activity decreases when individuals perceive their environment as constraining or controlling (Kurtzberg \& Amabile, 2000-2001).

According to the social network theory, social interactions among members in a network results in flows of resources (Burt, 1992; Granovetter, 1973). Social networks comprise a set of connections, such as friends, relatives, and business partners who know and trust each another. These connections help entrepreneurs recognize, evaluate, and exploit opportunities by combining the resources of the network members (Burt, 1992). When there is high power distance, the class, power, and status of members of the society determine who has access to resources (Luczak et al., 2010). In high power distance societies, such as India, resources and networks are more available to upper-class individuals (Chen \& Tan, 2009; Drori et al., 2009; Patel \& Conklin, 2009). The stratified social system determines the social status of individuals in the Indian society and individuals have advantages or disadvantages depending on the position occupied by their group within the social hierarchy (Dumont, 1970; Joseph \& Selvaraj, 2010). Researchers have suggested disadvantages of certain groups in business activities due to their group membership (Vaid, 2014).

Resources provided by the network may come in the form of financial, intellectual, or emotional support
(Muzychenko, 2008). Individuals who perceive a high power distance believe that the powerful have privileges and access to resources and mobility (Schnell et al., 1999; Zhou, 2004). We argue that power distance may influence opportunity evaluation by shaping an individual's perception of autonomy and their perspective on the availability of resources. For example, those who endorse high power distance are likely to view starting a new venture as something only the elite do and, therefore, they may not have the necessary mental models to scan for and evaluate new opportunities. Similarly, they are likely to feel alienated from the upper-class individuals and perceive that they don't have access to the network and resources that the elite have access to (Luczak et al., 2010; Zhou, 2004). Therefore, we hypothesize:

Hypothesis 1. Power distance will be negatively associated with a favorable evaluation of entrepreneurial opportunity.

Uncertainty avoidance refers to lack of tolerance for ambiguity and absence of structure (Dorfman \& Howell, 1988). People vary in their tolerance for ambiguity and risk (Hofstede, 1980). Some individuals are more anxious in accepting uncertainty than others. For those who avoid uncertainty, change and risk generate anxiety. Such individuals feel uncomfortable operating in unstructured and uncertain situations. They try to avoid uncertainty by setting strict rules and regulations, and prescribing guidelines for every possible scenario. Individuals who embrace uncertainty, on the other hand, demonstrate more risk taking as well as more tolerance toward unstructured, ambiguous situations (Hofstede \& Hofstede, 2005; Steensma et al., 2000).

The tendency to avoid uncertainty is likely to influence entrepreneurial behavior (Mitchell et al., 2002; Steensma et al., 2000). Opportunity evaluation, by definition, is fraught with ambiguity and uncertainty and it usually demands judgments made under complex or uncertain conditions. Opportunity evaluation is risky because the outcomes are unclear. When pursuing new opportunities, enterprising individuals are vulnerable to failure and loss. Individuals who avoid uncertainty are likely to perceive entrepreneurial opportunities as risky and, therefore, not favorable. Entrepreneurs are more likely to evaluate an opportunity favorably when they perceive less risk in that opportunity (Keh et al., 2002). Thus, individuals high on uncertainty avoidance are likely to stay away from favorably evaluating new opportunities. We hypothesize: 
Hypothesis 2. Uncertainty avoidance will be negatively associated with a favorable evaluation of entrepreneurial opportunity.

People differ in terms of their focus on the self as compared to the interest of the collective. As defined by Hofstede (1991), individualism is characterized by a belief in loose ties between individuals who are expected to look after themselves ahead of everyone else. Collectivism, on the other hand, pertains to believing in integrating people into strong, cohesive in-groups. These groups protect people in exchange for unquestioning loyalty. Individualists desire independence from any sort of group affiliation, whereas collectivists search out and value long-term group ties that are similar to an extended family (Triandis, 1993). Individualists give priority to personal goals over group goals whereas collectivists prioritize the welfare of the group. Collectivists are connected to their social networks from birth onwards and feel attached to groups of individuals they can trust and rely on (Luczak et al., 2010).

The protection and support provided by the group creates a safety net for the entrepreneur and reduces the uncertainty and the risk associated with starting a new business. These social networks create opportunities for entrepreneurs and help them acquire resources in the form of information, professional knowledge and skill, cultural capital, opportunities, and advice (Burt, 1992; Bratkovic \& Antoncic, 2009; Drori et al., 2009; Granovetter, 1973; Muzychenko, 2008; Portes et al., 1999). Networks (Shane et al., 1991; Todorovic \& Ma, 2008) and resource leverage provided by the group (Tiessen, 1997) are among the most cited factors that support entrepreneurship. Therefore, individuals who do not have collectivist values and are not a part of a collectivist group are both less likely to find the support to start an entrepreneurial venture and less likely to favorably assess new opportunities as worth pursuing. Therefore, we hypothesize:

Hypothesis 3. Collectivism will be positively associated with a favorable evaluation of entrepreneurial opportunity.

Masculinity refers to an overall preference for "toughness" and competitiveness, as opposed to modesty and humility, which form the opposite pole of femininity. Masculine values, also called instrumental values, are composed of assertiveness, competitiveness, independence, and aggressiveness. Feminine values, also called expressive values, refer to an affective concern for the welfare of others, cooperation, caring, nurturing, and the harmony of the group (Constantinople, 1973; Spence \& Helmreich, 1980; Bem, 1981; Williams \& Best, 1982).
Findings regarding the role of masculinity in the entrepreneurial process seem to be mixed. Research suggests that different qualities (i.e., masculine and feminine) are instrumental in different stages of the entrepreneurial process (Hamilton, 2013). We expect feminine values to be positively associated with the earlier, opportunity evaluation stage of the entrepreneurial process. Entrepreneurs face an uncertain and constantly changing environment, especially during the early stages of the entrepreneurial process. Adaptability and flexibility are essential to successfully perform many entrepreneurial tasks. The entrepreneur must possess feminine qualities of adaptability, flexibility, and resilience. While searching and evaluating opportunities, entrepreneurs rely on creative skills, which are feminine values, to develop novel ideas and evaluate market opportunities to create a product, a service, or a new venture (Mueller \& Dato-on, 2008). For example, while a masculine emphasis on assertiveness may be a required quality when bargaining with suppliers, it may play a negative role in the opportunity evaluation stage of the entrepreneurial process. During the opportunity evaluation process, which involves searching for, connecting, and making sense of information, we expect relational qualities to be critical. Feminine qualities have been positively linked to perseverance, mutual empowerment, achievement, and the creation of teams (Fletcher, 1998). Individuals who persevere are more likely to evaluate opportunities favorably, and those who can create empowered teams and mutual cooperation are likely to pool resources and build a network of support for themselves. Therefore, we hypothesize:

Hypothesis 4. Femininity will be positively associated with a favorable evaluation of entrepreneurial opportunity.

To summarize, we predict that power distance and uncertainty avoidance will be negatively related to a favorable evaluation of new business opportunities, whereas femininity and collectivism will be positively related to a favorable evaluation of new business opportunities (at least, in high power distance societies like India as we discussed earlier). In the next section, we discuss the methodology used to test our predictions.

\section{METHOD}

\section{Data and Sample}

We collected data from business students at a large private university in southern India. A total of 267 students (164 men, 56 women, and 47 unreported) completed

10 NEW ENGLAND JOURNAL OF ENTREPRENEURSHIP 
the English-language survey in class. In our sample, $6 \%$ of the respondents identified themselves as upper class, $74 \%$ identified themselves as middle class, and about 20\% identified themselves as working class or lower. Twentyeight percent of the respondents were graduate students and $72 \%$ of the students were undergraduate students. The average age of our sample was 22 years, which is consistent with the age at which early-stage entrepreneurial activity is most common (Hisrich et al., 2007). According to the Global Entrepreneurship Monitor, global trends show that both entrepreneurial intentions and entrepreneurial activity are the highest among the 18-44 age group. GEM National Expert Survey suggests that India has an advantage in entrepreneurship with its young population: about $63 \%$ of the population is in the 15-59 age group.

We chose business students as our sample for several reasons. First, we sought participants who are familiar with the business world and with the concept of entrepreneurship (Begley et al., 2005). Second, we wanted respondents who have not yet decided on a corporate career and are likely to be interested in starting their own business in the future (Mueller \& Thomas, 2000). Lastly, business students are believed to represent a significant share of the pool of entrepreneurially oriented individuals in developing countries (Gupta \& Fernandez, 2009), and there exists a strong emphasis among policy makers on encouraging business students to be entrepreneurial (Hisrich et al., 2007). GEM National Expert Survey also lists education as one of the main constraining factors for entrepreneurship in India. For these reasons, we believe that our sample of business students in India with average age of 22 years is an appropriate context for our study. No extra credit was given for participating in this study, but students were promised summary findings for participation.

\section{Measures}

Although Hofstede (1980) conceived culture at the societal level, there has been a growing trend in the literature to assess individual-level cultural values. Dorfman and Howell (1988) were the first to apply Hofstede's cultural dimensions to the individual level (Culpepper \& Watts, 1999; Mancheno-Smoak et al., 2009). Their scales are based on Hofstede's original definitions and are reliable at the individual level (Nicholson, 1991). This scale provides "insight to an individual's perception of culture as their personal values" (Mancheno-Smoak et al., 2009, p. 12). It is based on the assumption that nationality is not a direct determinant of cultural orientation but rather there may be value differences among individuals within a society. Various studies have validated the reliability and the validity of Dorfman and Howell's (1988) scale (Mancheno-Smoak et al., 2009; Culpepper \&Watts, 1999) to measure cultural dimensions at the individual level.

The Dorfman and Howell (1988) measure of cultural value orientation was used to measure respondents' ascriptions to the four values considered here on a fivepoint Likert scale. The following two items from the original Dorfman and Howell (1988) collectivism scale were deleted after factor and reliability analysis: "Being accepted by the members of your work group is very important", "Individuals may be expected to give up their goals in order to benefit group success". The scales had reliabilities (Cronbach alpha) of .63 (collectivism), .77 (uncertainty avoidance), .74 (femininity), and .75 (power distance) in our data. Although within the acceptable range, collectivism scale had relatively low reliability in this study as it did in the original Dorfman and Howell's (1988) study. It is possible that collectivism statements were interpreted differently in India. The collectivism scale has had low reliability in multiple studies conducted in cross-cultural contexts due to interpretation differences (Schwarz \& Oyserman, 2001; Shulruf et al., 2011).

Demographic questions asked participants to report their gender, age, work experience, socioeconomic status, and other such information. Following the vignette approach advocated in the opportunity evaluation literature (Keh et al., 2002; Gupta et al., 2014), we used a set of three opportunity evaluation vignettes that were adapted directly from Highhouse and colleagues (2002). These business-related scenarios "illustrate strategic issues and were shown to clearly represent opportunities" (Highhouse et al., 2002, p. 46). Participants responded to each of the three opportunity scenarios using a scale that ranged from $1=$ strongly disagree to $5=$ strongly agree. Previous research has often either used a singular scenario (e.g., Keh et al., 2002) or conducted separate statistical tests on each scenario (e.g., Conroy \& Emerson, 2004). Researchers have not yet offered a priori predictions based on theoretical considerations that the independent variable or predictor should be related to some but not other scenarios. Therefore, departing from past research, we adopted an analytic approach that combined responses to the three scenarios adopted from Highhouse et al. (2002), such that one common score served as the dependent variable (see Appendix). In addition, factor 
analysis of the three scenarios revealed a single factor with a good reliability of the measure as expected, since all questions pertain to opportunity evaluation. Our multiscenario approach offers a more conservative test of the relationships (that is, higher reliability and validity) than is possible with single-scenario studies.

\section{Analyses and Results}

The primary statistical techniques used to analyze data in this study included descriptive statistics, correlations, t-tests, and multivariate hierarchical regression. Table 1 presents descriptive statistics including means, standard deviations, and reliability for all measures as well as the correlation matrix (Pearson product moment correlations) for the variables in the study. The intercorrelations among the variables in this study were in line with expectations. All dimensions of culture including collectivism, uncertainty avoidance, femininity, and power distance were significantly related to opportunity evaluation. However, contrary to expectations, uncertainty avoidance had a positive relationship with opportunity evaluation.
None of the control variables other than socioeconomic status were significantly related to the dependent variable. Respondents to our survey were predominantly male. Therefore, we checked for homogeneity by conducting an independent sample t-test. We did not find any significant differences between males and females in terms of cultural values and opportunity evaluation.

Table 2 reports the results of hierarchical multivariate regression analyses for the dependent variable. To clearly distinguish control variables from independent variables, Socio Economic Status (SES) was entered first and independent variables were entered next into the regression model. SES was the only control variable included in the analyses. None of the other control variables were significantly related to opportunity evaluation; therefore, they were not included in the regression analysis. Model 1 presents regression results of the control variable on the dependent variable and Model 2 presents regression results of the independent variable on the dependent variable (see Table 2).

\section{Table 1}

\begin{tabular}{|c|c|c|c|c|c|c|c|c|c|c|c|}
\hline & Mean & Std. Deviation & Alpha & 1 & 2 & 3 & 4 & 5 & 6 & 7 & 8 \\
\hline Gender (1) & .25 & .44 & & 1 & & & & & & & \\
\hline Age (2) & 22.12 & 2.01 & & $-.19^{* *}$ & 1 & & & & & & \\
\hline $\begin{array}{l}\text { Socio-Economic } \\
\text { Status (SES) (3) }\end{array}$ & 2.85 & .84 & & .04 & .00 & 1 & & & & & \\
\hline Collectivism (4) & 3.91 & .67 & .63 & .10 & .02 & -.12 & 1 & & & & \\
\hline Femininity (5) & 2.69 & .90 & .74 & .11 & .11 & $-.16^{*}$ & .12 & 1 & & & \\
\hline Power Distance (6) & 2.67 & .92 & .75 & .05 & $-.19^{* *}$ & $.20^{*}$ & $-.14^{*}$ & $.62^{* *}$ & 1 & & \\
\hline Uncertainty Avoidance (7) & 4.27 & .72 & .77 & -.05 & .05 & $-.16^{*}$ & $.44^{* *}$ & $-.23^{* *}$ & $-.28^{* *}$ & 1 & \\
\hline Opportunity Evaluation (8) & 3.86 & .64 & .89 & .02 & .11 & $-.18^{*}$ & $.26^{* *}$ & $.55^{* *}$ & $-.52^{* *}$ & $.55^{* *}$ & 1 \\
\hline
\end{tabular}

12 NEW ENGLAND JOURNAL OF ENTREPRENEURSHIP 
Results show a significant negative relationship between power distance and opportunity evaluation as predicted in hypothesis $1(\beta=-.196, p<.01)$. Results also suggest a significant positive relationship between femininity $(\beta=.229, p<.01)$ and opportunity evaluation. Therefore, hypothesis 4 was supported. Although there was a significant relationship between uncertainty avoidance and opportunity evaluation $(\beta=.41, p<.001)$, contrary to expectations it was a positive relationship; therefore, hypothesis 2 was not supported. There was no significant relationship between collectivism and opportunity evaluation and hypothesis 3 was not supported. In all, we found empirical support for $\mathrm{H} 1$ and $\mathrm{H} 4$ in our data, but $\mathrm{H} 2$ and $\mathrm{H} 3$ failed to be supported.

Table 2

\section{Results of the Hierarchical Regression Analysis for all Independent Variables}

\section{Independent Variables}

\section{Variables}

Model 1

(Controls only)

\section{Model 2}

(Independent Variables)

\section{Control Variable}

.015

\section{Independent Variables}

Power Distance

$-.196^{*}$

Uncertainty Avoidance

$.410^{* * *}$

Femininity

$.229^{* *}$

Collectivism

$-.020$

\begin{tabular}{lcc}
\hline Constant & $4.231^{* * *}$ & $2.455^{* * *}$ \\
F & 1.782 & $30.301^{* * *}$ \\
R2 & .013 & .484 \\
Adjusted R2 & .006 & .464 \\
Change in R2 & .013 & .471 \\
Number of Observations & 253 & 253 \\
\hline
\end{tabular}

Notes: Table presents standardized coefficients. $+p<.1,{ }^{*} p<.05,{ }^{* *} p<.01,{ }^{* * *} p<.001$ 


\section{Post-hoc Analyses}

We conducted a post-hoc test to increase confidence in our findings. We ran regression with each of the four cultural values entered separately and opportunity evaluation as the dependent variable. We find that, as predicted, power distance $(\beta=-.52, p<.001)$ and femininity $(\beta=.53, p<.01)$ were positively related to opportunity evaluation. Uncertainty avoidance was also significantly related to opportunity evaluation $(p<.001)$; however, contrary to the hypothesis, it was a positive relationship. We did not find a significant relationship between collectivism and opportunity evaluation.

\section{DISCUSSION}

Entrepreneurial activity is a result of individuals favorably evaluating business opportunities to introduce new goods and services (Chiles et al., 2007). Although conventional economic wisdom advocated an objective value-based perspective of business opportunities, recent research recognizes individual differences in the evaluation of opportunities (Mitchell \& Shepherd, 2010). In this study, we examined the relationship between individual cultural values and opportunity evaluation. We found that the power distance value is negatively associated with opportunity evaluation, whereas the femininity value is positively associated with opportunity evaluation. Our results suggest that those who view the world in an egalitarian way and show a preference for agreeableness and relationships are more likely to evaluate new opportunities favorably. As such, we contribute to the knowledge of factors underlying opportunity evaluation (Eckhardt \& Shane, 2003) as well as the impact of individual cultural values on opportunity evaluation (Kirkman et al., 2009).

Contrary to our expectations, there was a significant and positive relationship between uncertainty avoidance values and opportunity evaluation. One possible explanation of this finding is that entrepreneurs are "risk eliminators" rather than "risk takers" (Zimmerer, Scarborough, \&Wilson, 2008), and that they plan and take calculated risks. A high uncertainty avoidance orientation may be associated with attention to detail and a motivation to study the situation in detail. After studying the situation and eliminating risks, self-efficacy of enterprising individuals may increase such that they become more likely to perceive opportunities (Goktan \& Gunay, 2011). Another explanation is that the positive relationship between uncertainty avoidance and opportunity evaluation we found is a result of collecting data in a country that usually scores high on uncertainty avoidance as a national characteristic (Hofstede, 1980). Perhaps, the strong emphasis on uncertainty avoidance at the national level motivates a stronger proclivity toward opportunity evaluation in individuals who tend to avoid uncertainty. Clearly, more research is needed to cast light on the role of uncertainty avoidance in evaluating new opportunities.

In recent years, researchers have focused on androgynous orientation in relation to entrepreneurship. Studies in the area suggest that both feminine and masculine values are related to entrepreneurship (e.g., Goktan \& Gupta, 2015; Heilman \& Chen, 2003; Jennings \& McDougald, 2007) despite the perception that business ownership is stereotypically masculine (Gupta et al., 2009). Studies suggest that masculine and feminine values play different roles in different phases of the entrepreneurial process (Hamilton, 2013). Some tasks in the entrepreneurial process require feminine qualities (Mueller \& Dato-on, 2008), such as concern for the welfare of others, harmony of the group, cooperation, adaptability, flexibility, caring, and nurturing (Brescoll et al., 2012; Hofstede \& Bond, 1984). Some situations (e.g., dealing with suppliers or investors), on the other hand, call for masculine qualities such as assertiveness (Mueller \& Dato-on, 2008). Future studies should examine the comparative role of masculine, feminine, and androgynous values in relation to opportunity evaluation.

Researchers draw attention to the fact that there is confusion around the meaning of collectivism and individualism. According to Brewer and Chen (2007), collectivism has "been criticized as being ill-defined and 'a catchall'to represent all forms of cultural differences" (p. 133). Voronov and Singer (2002) add that "individualism-collectivism research is characterized largely by insufficient conceptual clarity." For example, in a metaanalysis of 83 studies, Oyserman, Coon, and Kemmelmeier (2002) identified eight major domains relating to collectivism (sense of duty to group, relatedness to others, seeking others' advice, harmony, working in groups, sense of belonging to a group, contextual self, valuing hierarchy). Collectivism scale has had low reliability issues especially in studies conducted in cross-cultural contexts (Dorfman \& Howell, 1988; Schwarz \& Oyserman, 2001; Shulruf et al., 2011) and it may partially be explained by its multidimensionality and the lack of a clear construct definition. Future studies should further examine the relationship between collectivism and opportunity evaluation.

14 NEW ENGLAND JOURNAL OF ENTREPRENEURSHIP 
The cultural values literature involves a paradox: Although Hofstede (1980) was clear that his framework was intended only for the country level, researchers have liberally adapted it to derive and test theories about the cultural antecedents of individual outcomes in the workplace (Taras et al., 2010). Prior research on individuallevel cultural values preferred to focus on singular dimensions (Kirkman et al., 2006), and few studies have been published in this area using all four Hofstede (1980) cultural dimensions (Niranjan et al., 2013). Furthermore, research often tends to fall back on Hofstede's (1980) country scores as proxies for individual-level cultural values rather than directly assess beliefs and values at the individual level (Kirkman et al., 2006). To construct a more complete picture of the effects of cultural values, we developed a coherent theory about different cultural value effects at the individual level and tested it using data collected in a specific country. Our findings suggest a significant relationship between individual cultural values and opportunity evaluation while also suggesting that this relatively new area requires further attention.

\section{LIMITATIONS AND DIRECTIONS FOR FUTURE RESEARCH}

We acknowledge certain limitations of our study, which also open directions for additional research. Although the four-dimensional cultural framework dominates research in the international arena (Niranjan et al., 2013), there are several other cultural values that have been proposed over the years (Taras et al., 2009). It is highly unlikely that a single model will cover all aspects of such a highly complex, multidimensional and multilayered phenomenon as cultural values. Future research should examine the additional variance contributed by other values (perhaps borrowing from less popular frameworks) in explaining the evaluation of new business opportunities. Comparative research weighing the relative contributions of different cultural frameworks (such as GLOBE or Schwartz) would be helpful in unraveling their usefulness in understanding new opportunity evaluation.

While Hofstede (1980) conceptualized cultural dimensions as bipolar, recent studies have proposed that these bipolar dimensions may actually be independent unipolar dimensions (Constantinople, 2005; Sharma, 2010). In other words, for example, masculinity and femininity may be independent dimensions rather than two ends of the same spectrum. Several studies indicate that masculinity is implicit in entrepreneurship (Lewis, 2006;
Marlow, 2002). However, researchers also emphasize that feminine qualities are also crucial in the entrepreneurial process (Brescoll et al., 2012; Mueller \& Dato-on, 2008). Future studies should examine androgyny, which refers to equal endorsement of both masculine and feminine identity, in relation to entrepreneurship (Goktan \& Gupta, 2015; Spence \& Helmreich, 1980. We theorized and tested our predictions in one country. Our approach has the advantage of holding extraneous factors constant (e.g., laws related to participation of men and women in the workforce). Yet, following Cook and Campbell (1979) who noted that external validity is best viewed as a characteristic of a stream of research and not a single study, we encourage future research to examine the generalizability of our results to other societies. It would be especially helpful to explore the relationships between cultural values and opportunity evaluation in countries that are very different from the Indian context in which we conducted the present study.

Finally, generalizability of results reported in this study to populations with more experience in evaluating new opportunities cannot be assumed and needs to be empirically confirmed. Prior research indicates some differences between novice and experienced entrepreneurs in assessing new venture ideas (Baron \& Ensley, 2006). Future research could test the validity of the relationships proposed here in populations with entrepreneurial experience.

Notwithstanding the limitations of our research, our study has several methodological strengths. First, we tested our hypotheses in India, which enabled us to respond to calls for research "in countries that are emerging as important global players and at the same time have sociocultural contexts very different from those of western countries" (Nadkarni \& Herrmann 2010, p. 1067). Second, the participants of this research study fell in the 18-24 age group, which has the lowest proportion of people in India who attribute their pursuit of new opportunities to "push" factors such as lack of alternative employment (Manimala, 2002). Third, unlike prior research, we used a multivignette approach to measure evaluation of new business opportunities, which provides for a stronger and more robust measure of opportunity evaluation. Finally, although the nature of the research participants' experiences did not exactly mirror those of a real organizational situation, several features of this task and of our participants achieved what Berkowitz and Donnerstein (1982) referred to as "mundane 
realism."To summarize, we have confidence that cultural values help explain variations in opportunity evaluation as we found in our study, and we encourage additional research in other settings to empirically examine the generalizability of our findings across populations, time periods, and dependent variables.

\section{CONCLUSION}

Our research advances extant literature by examining the relationship between cultural values and opportunity evaluation at the individual level. Entrepreneurship researchers seek to delve deeper into the linkages that connect cultural values like power distance, uncertainty avoidance, femininity, and collectivism with opportunity evaluation, as we theorized and validated in this study.
Our logic connecting cultural values directly with opportunity evaluation is supported for opportunity evaluation linking negatively with power distance and positively with femininity. Our findings also reveal that the association of uncertainty avoidance and collectivism with opportunity evaluation is more complex than previously realized. We acknowledge that our single-nation study —-theorizing and testing predictions in India-may constrain the external validity of our findings. Comparative studies between different regions in the same country or between different countries will help extend the generalizability of our research.

\section{REFERENCES}

Amabile, T.M., Conti, R., Coon, H., Lazenby, J. and Herron, M. (1996). Assessing the work environment for creativity. Academy of Management Journal, 39(5), 1154-1184.

Ashforth, B., \& Mael, F. (1989). Social identity theory and the organization. Academy of Management Review, 14, $20-39$.

Baron, R. A., \& Ensley, M. D. (2006). Opportunity recognition as the detection of meaningful patterns: Evidence from comparisons of novice and experienced entrepreneurs. Management Science, 52(9), 1331-1344.

Baskerville, R. F. (2003). Hofstede never studied culture. Accounting, Organizations and Society, 28(1), 1-14.

Begley, T. M., Tan, W. L., \& Schoch, H. (2005). Politico-economic factors associated with interest in starting a business: A multi-country study. Entrepreneurship Theory \& Practice, 29, 35-44.

Bell, D.N.F \& Blanchflower D.G. (2011). UK underemployment in the Great Recession. National Institute Economic Review, 215, $23-33$.

Bem, S. L. (1981). Gender schema theory: A cognitive account of sex typing. Psychological Review, 88, 354-364.

Berkowitz, L. \& Donnerstein, E. (1982). External validity is more than skin deep: Some answers to criticisms of laboratory experiments. American Psychologist, 37(3), 245-257.

Brandstätter, H. (2011). Personality aspects of entrepreneurship: A look at five meta-analyses. Personality \& Individual Differences, 51(3), 222-230.

Bratkovic, T. \& Antoncic, B. (2009). Networking of copreneurs and small firm growth: Personal sub networks analysis. Zagreb International Review of Economics and Business, 12(2), 33-56.

Brescoll, V. L., Uhlmann, E. L., Moss-Racusin, C., \& Sarnell, L. (2012). Masculinity, status, and subordination: Why working for a gender stereotype violator causes men to lose status. Journal of Experimental Social Psychology, 48(1), 354-357.

Brewer, M. B., \& Chen, Y. (2007). Where (Who) are collectives in collectivism? Toward conceptual clarification of individualism and collectivism. Psychological Review, 114(1), 133-151.

Burt, R. S. (1992). Structural holes. Cambridge, MA: Harvard University Press.

16 NEW ENGLAND JOURNAL OF ENTREPRENEURSHIP 
Chan, K.-Y., \& Drasgow, F. (2001). Toward a theory of individual differences and leadership: Understanding the motivation to lead. Journal of Applied Psychology, 86, 481-498.

Chen, W. and Tan, J. (2009). Understanding transnational entrepreneurship through a network lens: Theoretical and methodological considerations". Entrepreneurship Theory and Practice, 33(5), 1079-91.

Chiles, T. H., Bluedorn, A. C., \& Gupta, V. K. (2007). Beyond creative destruction and entrepreneurial discovery: A radical Austrian approach to entrepreneurship. Organization Studies, 28, 467-493.

Collins, C. J., Hanges, P. J., \& Locke, E. A. (2004). The relationship of achievement motivation to entrepreneurial behavior: A meta-analysis, Human Performance, 17, 1; 95-117.

Colquitt, J. A. (2004). Does the justice of the one interact with the justice of the many? Reactions to procedural justice in teams. Journal of Applied Psychology, 89, 633-646.

Colquitt, J. A., Noe, R. A., \& Jackson, C. L. (2002). Justice in teams: Antecedents and consequences of procedural justice climate. Personnel Psychology, 55(1), 83-110.

Conroy, S. J., \& Emerson, T. L. N. (2004). Business ethics and religion: Religiosity as a predictor of ethical awareness among students. Journal of Business Ethics, 50(4), 383-396.

Constantinople, A. (1973). Masculinity-femininity: An exception to the famous dictum? Psychological Bulletin, 80, $389-407$.

Constantinople, A. (2005). Masculinity-femininity: An exception to a famous dictum? Feminism and Psychology, 15(4), 385-407.

Cook, T. D., \& Campbell, D. T. (1979). Quasi-experimentation: Design and analysis issues for field settings. Boston, MA: Houghton Mifflin Company.

Culpepper, R., \&Watts, L. (1999). Measuring cultural dimensions at the individual level: An examination of the Dorfman and Howell (1988) scales and Robertson and Hoffman (1999) scale. Academy of Strategic and Organizational Leadership Journal, 3(1), 22-34.

Dorfman, P. W., \& Howell, J. P. (1988). Dimensions of national culture and effective leadership patterns: Hofstede revisited. Advances in International Comparative Management, 3, 127-150.

Drori, I., Honig, B., \& Wright, M. (2009). Transnational entrepreneurship: An emergent field of study. Entrepreneurship Theory and Practice, 33(5), 1001-22.

Dumont, L. (1970). Homo hierarchicus: The caste system and its implications. Chicago and London: The University of Chicago Press.

Eckhardt, J., \& Shane, S., (2003). The importance of opportunities to entrepreneurship. Journal of Management, 29(3), 333-349.

Emrich, C. G., Denmark, F. L., \& Den Hartog, D. N. (2004). Cross-cultural differences in gender egalitarianism: Implications for societies, organizations and leaders. In R.J. House, P. J. Hanges, M. Javidan, P. W. Dorfman, V. Gupta \& GLOBE associates (Eds.), Cultures, leadership and organizations: A 62 nation GLOBE study, 1.

Etemad, H. (2004). International entrepreneurship as a dynamic adaptive system: Towards a grounded theory. Journal of International Entrepreneurship, 2(1/2), 5-59.

Fine, G. A. (1993). The sad demise, mysterious disappearance and glorious triumph of symbolic interactionism. Annual Review of Sociology, 19, 61-87.

Fletcher, J. (1998). Relational practice: A feminist reconstruction of work. Journal of Management Inquiry, 7(2), 163-186.

Foo, M. (2011). Emotions and entrepreneurial opportunity evaluation. Entrepreneurship Theory and Practice, 35(2), 375-393.

RELATING CULTURAL VALUES WITH OPPORTUNITY EVALUATION 17 
Goktan, A. B., \& Gunay, G. (2011). Is entrepreneurial cognition culturally bound? A comparative study conducted in Turkey and the United States. Journal of Small Business \& Entrepreneurship, 24(4), 455-69.

Goktan, A.B. \& Gupta, V.K. (2015). Sex, gender, and individual entrepreneurial orientation: Evidence from four countries. International Entrepreneurship and Management Journal, 11(1), 95-112.

Gomez, C., Kirkman, B. L., \& Shapiro, D. L. (2000). Reward allocation preferences in Mexico and the United States: The effects of ingroup/outgroup status and collectivism. Academy of Management Journal, 43(6), 1097-1106.

Granovetter, M. S. (1973). The strength of weak ties. American Journal of Sociology, 78, 1360-80.

Gupta, V. K., \& Fernandez, C. (2009). Cross-cultural similarities and differences in characteristics attributed to entrepreneurs: A three nation study. Journal of Leadership \& Organizational Studies, 15(3), 304-318.

Gupta, V. K., Goktan, A. B., \& Gunay, G. (2014).Gender differences in evaluation of new business opportunity: A stereotype threat perspective, Journal of Business Venturing, 29, 273-288.

Gupta, V. K., Turban, D. B., Wasti, S. A., \& Sikdar, A. (2009). The role of gender stereotypes in perceptions of entrepreneurs and intentions to become an entrepreneur. Entrepreneurship Theory and Practice, 33(2), 397-417.

Hamilton, E. (2013). The discourse of entrepreneurial masculinities (and femininities). Entrepreneurship \& Regional Development: An International Journal, 25(1-2), 90-99.

Haynie, J. M., Shepherd, D. A., \& McMullen, J. S., (2009). An opportunity for me? The role of resources in opportunity evaluation decisions. Journal of Management Studies, 46, 337-361.

Hayton, J. C., George, G. \& Zahra, S. A. (2002). National culture and entrepreneurship: A review of behavioral research, Entrepreneurship Theory and Practice, 26, 33-52.

Heilman, M. E., \& Chen, J. J. (2003). Entrepreneurship as a solution: The allure of self-employment for women and minorities. Human Resource Management Review, 13(12), 347-364.

Highhouse, S., Hoffman, J.R., Greve, E.M., \& Collins, A.E. (2002). Persuasive impact of organizational value statements in a recruitment context. Journal of Applied Social Psychology, 32, 1737-1755.

Hisrich, R., Langan-Fox, J., \& Grant, S. (2007). Entrepreneurship research and practice: A call to action for psychology. American Psychologist, 62, 6-14.

Hofstede, G. (1980). Culture's consequences: National differences in thinking and organizing. Beverly Hills, California: Sage.

Hofstede, G. (1991). Software of the mind. Maidenhead, UK: McGraw-Hill.

Hofstede, G. (1998). Masculinity and femininity: The taboo dimension of national cultures. Thousand Oaks CA: Sage Publications.

Hofstede, G. (2001). Culture's Consequences: Comparing Values, Behaviors, Institutions, and Organizations Across Nations. 2nd Edition, Thousand Oaks CA: Sage Publications.

Hofstede, G. (2002). Dimensions do not exist: A reply to Brendan McSweeney. Human Relations, 55(11), 1355-1361.

Hofstede, G. (2006). What did GLOBE really measure? Researchers' minds versus respondents' minds. Journal of International Business Studies, 37(6), 882-896.

Hofstede, G., \& Bond, M. H. (1984). Hofstede's culture dimensions: An independent validation using Rokeach's value survey. Journal of Cross-Cultural Psychology, 15(4), 417-433.

Hofstede, G., \& Hofstede, G. (2005). Cultures and organizations: Software of the mind. 2nd Edition, McGraw Hill USA.

18 NEW ENGLAND JOURNAL OF ENTREPRENEURSHIP 
Hofstede, G., Hofstede, G. J., and Minkov, M. (2010). Cultures and Organizations: Software of the Mind. 3rd Edition. New York: McGraw-Hill USA.

Jennings, J. E., \& McDougald, M. S. (2007). Work-family interface experiences and coping strategies: Implications for entrepreneurship research and practice. Academy of Management Review, 32, 747-760.

Joseph, J., \& Selvaraj, P. (2010). Caste and social emancipation through retail entrepreneurship networks: An ethnographic exploration of the Nadar caste in southern India. International Journal of Interdisciplinary Social Sciences, 5(1), 401-411.

Kagitcibasi, C. (1997). Individualism and collectivism. In J. F. Berry,M. H. Segall, \& C. Kagitcibasi (Eds.), Handbook of crosscultural psychology, 3, 1-49. London: Allyn \& Bacon.

Keh, H., Foo, M., \& Lim, B. (2002). Opportunity evaluation under risky conditions: The cognitive processes of entrepreneurs. Entrepreneurship Theory \& Practice, 27(2), 125-148.

Khanna, P. (2008). Here comes the second world. New Perspectives Quarterly, 25, 13-17.

Kirkman, B, Chen, G, Farh, J, Chen, Z \& Lowe, K (2009). Individual power distance orientation and follower reactions to transformational leaders: A cross-level, cross-cultural examination, Academy of Management Journal, 52(4), 744-764.

Kirkman, B. L., \& Shapiro, D. L. (2001). The impact of cultural values on job satisfaction and organizational commitment in self-managing work teams: The mediating role of employee resistance. The Academy of Management Journal, 44(3), 557-569.

Kirkman, B. L., Lowe, K. B., \& Gibson, C. B. (2006). A quarter century of culture's consequences: A review of the empirical research incorporating Hofstede's cultural value framework. Journal of International Business Studies, 37, 285-320.

Kurtzberg, T. R., \& Amabile, T. M. (2000-2001). From Guilford to creative synergy: Opening the black box of team-level creativity. Creativity Research Journal, 13(3 \& 4), 258-294.

Levitin, T. (1973). Values, In: J.P. Robinson and P.R. Shaver (eds.) Measures of social psychological attitudes, institute for social research. Ann Arbor, MI: Institute for Social Research, pp: 489-502.

Lewis, P. (2006). The quest for invisibility: Female entrepreneurs and the masculine norm of entrepreneurship. Gender, Work and Organization, 13, 453-469.

Liñán, F., \& Chen, Y. W. (2009). Development and cross-cultural application of a specific instrument to measure entrepreneurial intentions. Entrepreneurship Theory and Practice, 33(3), 593-617.

Luczak, C., Mohan-Neill, S., \& Hills, G. (2010). National culture, market orientation and network-derived benefits: Conceptual model for service SME's. Academy of Entrepreneurship Journal, 16(2), 1-20.

Mancheno-Smoak, L., Endres, G. M., Polak, R., \& Athanasaw, Y. (2009). The individual cultural values and job satisfaction of the transformational leader. Organization Development Journal, 27(3), 9-21.

Manimala, M. J. (2002). Founder characteristics and start-up policies of entrepreneurial ventures: A comparison between British and Indian enterprises. Journal of Entrepreneurship, 11, 139-171.

Marlow, S. (2002). Women and self-employment: A part of or apart from theoretical construct? International Journal of Entrepreneurship and Innovation, 3(2), 83-91.

McSweeney, B. (2002). Hofstede's model of national cultural differences and their consequences: A triumph of faith-a failure of analysis. Human Relations, 55(1), 89-118.

Mitchell, J. R., \& Shepherd, D. A., (2010). To thine own self be true: Images of self, images of opportunity, and entrepreneurial action. Journal of Business Venturing, 25, 138-154. 
Mitchell, R. K., Busenitz, L., Lant, T., McDougall, P. P., Morse, E. A. \& Smith, B. (2002). Entrepreneurial cognition theory: Rethinking the people side of entrepreneurship research. Entrepreneurship: Theory \& Practice, 27(2), 93-104.

Mitchell, R. K., Smith, B., Seawright, K.W., \& Morse, E.A. (2000). Crosss-cultural cognitions and the venture creation decision. Academy of Management Journal, 43(5), 974-993.

Moorman, R. H., \& Blakely, G. L. (1995). Individualism-collectivism as an individual difference predictor of organizational citizenship behavior. Journal of Organizational Behavior, 16, 127-142.

Mueller, S. L., \& Dato-on, M.C. (2008). Gender-role orientation as a determinant of entrepreneurial self-efficacy. Journal of Developmental Entrepreneurship, 13(1), 3-20.

Mueller, S. L., \& Thomas, A. S. (2000). Culture and entrepreneurial potential: A nine country study of locus of control and innovativeness. Journal of Business Venturing, 16, 51-75.

Muzychenko, O. (2008). Cross-cultural entrepreneurial competence in identifying international business opportunities. European Management Journal, 26, 366-77.

Nadkarni, S., \& Herrmann, P. (2010). CEO personality, strategic flexibility, and firm performance: The case of the Indian business process outsourcing industry. Academy of Management Journal, 53, 1050-1073.

Nicholson, J. D. (1991). The relationship between cultural values, work belief, and attitudes towards socio economic issues: A cross cultural study. Unpublished doctoral dissertation, Florida State University.

Niranjan, S., Gupta, V. K., Goktan, A. B. Cheung, Y., Gunay, G., \& Pareek, A. (2013). Cultural value orientation: Measurement invariance in a multi-country sample. Journal of Managerial Issues, 25(3), 264-283.

Oyserman, D., Coon, H. M., \& Kemmelmeier, M. (2002). Rethinking individualism and collectivism: Evaluation of theoretical assumptions and meta-analyses. Psychological Bulletin, 128(1), 3-72.

Patel, P.C. and Conklin, B. (2009). The balancing act: The role of transnational habitus and social networks in balancing transnational entrepreneurial activities. Entrepreneurship Theory and Practice, 33, 1045-78.

Portes, A., Guarnizo, L. E., \& Landolt, P. (1999). The study of transnationalism: Pitfalls and promise of an emergent research field. Ethnic and Racial Studies, 22(2), 217-37.

Ralston, D. A., Holt, D. H., Terpstra, R. H., \& Kai-Cheng, Y. (2007). The impact of national culture and economic ideology on managerial work values: A study of the United States, Russia, Japan, and China. Journal of International Business Studies, 39, 8-26.

Rauch, A. and M. Frese (2007), 'Let's put the person back into entrepreneurship research: A meta-analysis on the relationship between business owners' personality traits, business creation and success.' European Journal of Work and Organizational Psychology, 16, 353-385.

Robert, C. Probst, T. M. Martocchio, J. J., Drasgow, F. \& Lawler, J. J. (2000). Empowerment and continuous improvement in the United States, Mexico, Poland, and India: Predicting fit on the basis of the dimensions of power distance and individualism. Journal of Applied Psychology, 85(5), 643-658.

Robert, C., \&Wasti, S.A. (2002). Organizational individualism and collectivism, theoretical development and an empirical test of a measure. Journal of Management, 28(4): 544-566.

Rokeach, M. (1973). The nature of human values. New York, NY: The Free Press.

Schnell, I., Benenson, I., \& Sofer, M. (1999). The spatial pattern of Arab industrial markets in Israel. Annals of the Association of American Geographers, 89(2), 31-6.

20 NEW ENGLAND JOURNAL OF ENTREPRENEURSHIP 
Schwartz, S. H. (1992). Universals in the content and structure of values: Theoretical advances and empirical tests in 20 countries. Advances in Experimental Social Psychology, 25, 1- 65.

Schwartz, S., \& Bilsky, W. (1987). Toward a universal psychological structure of human values. Journal of Personality and Social Psychology, 53, 550-562.

Schwartz, S., \& Bilsky,W. (1990). Toward a theory of the universal content and structure of values: Extensions and crosscultural replications. Journal of Personality and Social Psychology, 58, 878-891.

Schwarz, N., \& Oyserman, D. (2001). Asking questions about behavior: Cognition, communication, and questionnaire construction. American Journal of Evaluation, 22, 127-160.

Schumpeter, J. (1934). Capitalism, socialism, and democracy. New York: Harper \& Row.

Shane, S. \& Eckhardt, J. (2005). The individual-opportunity nexus. Handbook of Entrepreneurship Research, 1, 161-191.

Shane, S. \& Venkataraman, S. (2000). The promise of entrepreneurship as a field of research. Academy of Management Review, $25,217-226$.

Shane, S., Kolvereid, L., \& Westhead, P. (1991). An exploratory examination of the reasons leading to new firm formation across country and gender. Journal of Business Venturing, 6, 431-46.

Sharma, P. (2010). Measuring personal cultural orientations: Scale development and validation. Journal of the Academy of Marketing Science, 38(6), 787-806.

Shepherd, D. A., \& DeTienne, D. R. (2005). Prior knowledge, potential financial reward, and opportunity identification. Entrepreneurship Theory \& Practice, 29(1), 91-112.

Shinnar, R. S., Giacomin, O., \& Janssen, F. (2012). Entrepreneurial perceptions and intentions: The role of gender and culture. Entrepreneurship Theory \& Practice, 36, 465-493.

Shulruf, B., Alesi, M., Ciochina, L., Faria, L., Hattie, J., Fu, H., \& ... Watkins, D. (2011). Measuring collectivism and individualism in the third millennium. Social Behavior \& Personality: An International Journal, 39(2), 173-187.

Smith, A., \& Hume, E.C. (2005). Linking culture and ethics: A comparison of accountants' ethical belief systems in the individualism/collectivism and power distance contexts. Journal of Business Ethics, 62(3), 209.

Smith, P. (2002). Culture's consequences: Something old and something new. Human Relations, 55(1), 119-135.

Spence, J. T., \& Helmreich, R.L. (1980). Masculine instrumentality and feminine expressiveness: Their relationships with sex role attitudes and behaviors. Psychology of Women Quarterly, 5, 147-163.

Steensma, H. K., Marino, L., \&Weaver, K. M. (2000). Attitudes toward cooperative strategies: A cross-cultural analysis of entrepreneurs. Journal of International Business Studies, 31(4), 591-609.

Stewart, W.H. Jr \& Roth, P.L. (2001). Risk propensity differences between entrepreneurs and managers: A meta-analytic review, Journal of Applied Psychology, 86(1), 145-53.

Taras, V., Kirkman, B. L., \& Steel, P. (2010). Examining the impact of culture's consequences: A three-decade, multilevel, metaanalytic review of Hofstede's cultural value dimensions. Journal of Applied Psychology, 95(3), 405-439.

Taras, V., Rowney, J., \& Steel, P. (2009). Half a century of measuring culture: Review of approaches, challenges, and limitations based on the analysis of 121 instruments for quantifying culture. Journal of International Management, 15(4), 357-373.

Taras, V., Steel, P., \& Kirkman, B. L. (2012). Improving national cultural indices using a longitudinal meta-analysis of Hofstede's dimensions. Journal of World Business, 47(3), 329-341. 
Thomas, A. \& Mueller, S. (2000). A case for comparative entrepreneurship: Assessing the relevance of culture. Journal of International Business Studies, 31(2), 287-301.

Tiessen, J. H. (1997). Individualism, collectivism, and entrepreneurship: A framework for international comparative research. Journal of Business Venturing, 12(5), 367-85.

Todorovic, Z. M. \& Ma, J. (2008). Entrepreneurial and market orientation relationship to performance: The multicultural perspective. Journal of Enterprising Communities: People and Places in the Global Economy, 1, 21-36.

Triandis, H. C. (1993). Collectivism and individualism as cultural syndromes. Cross-Cultural Research, 27, 155-180.

Triandis, H. C., Bontempo, R., Leung, K., \& Hui, C. H. (1990). A method for determining cultural, demographic, and personal constructs. Journal of Cross-Cultural Psychology, 21(3), 302.

Vaid, D. (2014). Caste in contemporary India: Flexibility and persistence. Annual Review of Sociology, 40, 391-410.

Van Maanen, J. (1989). Some notes on the importance of writing in organization studies. In J.I. Cash and P.R. Lawrence (eds.) The Information System Research Challenge: Qualitative Research Methods. Boston: Harvard Business School Press, 27-35.

Venaik, S., \& Brewer, P. (2010). Avoiding uncertainty in Hofstede and GLOBE. Journal of International Business Studies, 41, $1294-1315$.

Voronov, M., \& Singer, J. A. (2002). The myth of individualism-collectivism: A critical review. The Journal of Social Psychology, 4, 461-480.

Williams, J. E., \& Best, D. L. (1982). Measuring sex stereotypes. Beverly Hills, CA: Sage Publications Inc.

Zhao, H., Seibert, S. E., \& Lumpkin, G. T. (2010). The relationship of personality to entrepreneurial intentions and performance: A meta-analytic review. Journal of Management, 36, 381-404.

Zhao, H., \& Seibert, S. (2006). The big five personality dimensions and entrepreneurial status: A meta-analytic review. Journal of Applied Psychology, 91 (2), 259-271.

Zhou, M. (2004). Revisiting ethnic entrepreneurship: Convergencies, controversies, and conceptual advancements. International Migration Review, 38(3), 1040-74.

Zimmerer, T. W., Scarborough, N. M., \& Wilson, D. (2008). Essentials of entrepreneurship and small business management (5th ed.). New Jersey: Pearson Prentice Hall.

APPENDIX

\section{Cultural Values Items:}

Individualism/Collectivism

1. Welfare of the group is more important than individual rewards

2. Group success is more important than individual success

3. Being accepted by the members of your group (e.g., family, society) is very important (item deleted)

4. People should pursue their goals only after considering the welfare of the group

5. Managers should encourage loyalty to the group

6. Individuals may be expected to give up their goals in order to benefit the group (item deleted)

7. I believe that success of the group is more important than success of any one individual (item added)

22 NEW ENGLAND JOURNAL OF ENTREPRENEURSHIP 


\section{Masculinity/Femininity}

1. Meetings are usually run more effectively when they are chaired by a man

2. It is more important for men to have a professional career than it is for a woman to have a professional carrier

3. Men usually solve problems with logical analysis, woman usually solve problems with intuition

4. Solving organizational problems usually requires the active forcible approach that is typical of men

5. It is preferable to have a man in high level-position rather than a woman

\section{Power Distance}

1. Managers should make most decisions without consulting subordinates

2. Manager should use authority and power when dealing with subordinates

3. Managers should seldom ask for the opinions of employees

4. Managers should avoid off-the-job social contacts with employees

5. Employees should not disagree with management decisions

6. Managers should not delegate important tasks to employees

\section{Uncertainty Avoidance}

1. It is important to have job requirements and instructions spelled out in detail so that employees always know what they are expected to do

2. Managers should expect employees to closely follow instructions and procedures

3. Rules and regulations are important because they inform employees what the organization expects of them

4. Standard operating procedures are helpful to employees on the job

5. Instructions for operations are important to employees on the job

\section{The 3 Opportunity Evaluation Scenarios and the questions following each scenario:}

1) Imagine that you have decided to start a new printing and copying business. You have learned that a company that offers printing and copying services at very competitive prices is planning on eliminating some of its operations. Your location is one that it is considering leaving. This would leave a large base of potential customers for you. Your competitor is planning on cutting operations soon.

2) Imagine that you are the owner of a large movie theater. You have learned that a builder is considering some major construction in your immediate surroundings. This would include the building of an apartment complex and some restaurants, which would greatly increase your customer base. Should the builder decide to invest in your location, construction would begin soon.

3) Imagine that your family owns a large manufacturing company. You are one of the finalists for a government order that would ensure business throughout the decade. Such a contract would discourage potential competitors from entering into your unique product area. The government order would begin soon.

\begin{tabular}{lccccc}
\hline $\begin{array}{l}\text { Please indicate the extent to which you agree with the } \\
\text { following statements }\end{array}$ & $\begin{array}{c}\text { Strongly } \\
\text { Disagree }\end{array}$ & $\begin{array}{c}\text { Somewhat } \\
\text { Disagree }\end{array}$ & $\begin{array}{c}\text { Neutral } \\
\text { 1. This situation is likely to result in a successful outcome for you }\end{array}$ & $\begin{array}{c}\text { Somewhat } \\
\text { Agree }\end{array}$ & $\begin{array}{c}\text { Strongly } \\
\text { Agree }\end{array}$ \\
\hline 2. This situation represents an opportunity & 1 & 2 & 3 & 3 & 4 \\
\hline 3. This situation is positive & 1 & 2 & 3 & 4 & 5 \\
\hline 4. You may gain in this situation and are unlikely to lose & 1 & 2 & 3 & 4 & 5 \\
\hline
\end{tabular}




\section{ABOUT THE AUTHORS}

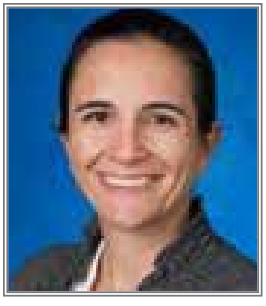

Banu A. Goktan is Associate Professor at the University of North Texas at Dallas. Her research interests are in the areas of entrepreneurship, innovation, and international management. Dr. Goktan's work has been published in Journal of Business Venturing, International Entrepreneurship and Management Journal, and Journal of Managerial Issues, among others.

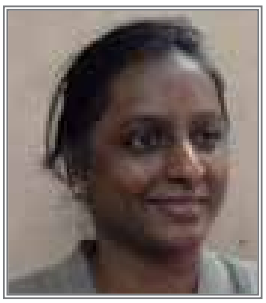

Alka Gupta is currently visiting professor at Indian Institute of Management at Rohtak (India). She has previously taught at Indian Institute of Technology and Lynchburg College. She received her PhD in Business Administration from SUNY-Binghamton. Dr. Gupta's research interests include entrepreneurial orientation and decision-making dynamics under crisis situations. She has published in journals such as Organization Research Methods and Leadership Quarterly.

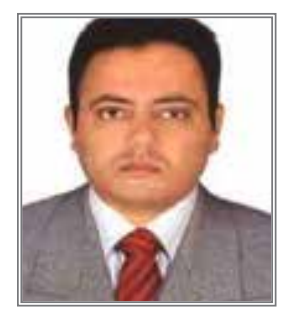

Subhendu Mukherjee is currently pursuing his PhD in Marketing Management. Before starting his PhD, he worked for four years in the corporate world. He has about seven years of teaching experience, including teaching courses in entrepreneurship, strategic management, export management, and international business.

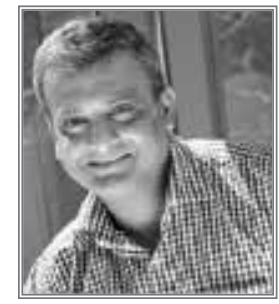

Vishal K. Gupta is Associate Professor at the University of Alabama. His research interests are in the areas of entrepreneurial leadership, corporate governance, and strategic issues in entrepreneurship. His work has been published in leading academic outlets such as Journal of Applied Psychology, Academy of Management Review, Journal of Business Venturing, Organization Studies, and Entrepreneurship Theory \& Practice, among others. 